SEÇÃO EXTRA

RESENHA

\title{
DISABILITY RIGHTS AND WRONGS REVISITED
}

\author{
Alessandra Moraes \\ de Sousa \\ Doutoranda em Teorias \\ Jurídicas Contemporâneas \\ do PPGD/UFRJ. Mestre em \\ Direito pela Universidade \\ Federal do Rio de Janeiro. \\ Pós-graduada (lato sensu) \\ em Direito Público pelo \\ Centro Universitário de \\ Volta Redonda (UniFoa). \\ Graduada em Direito pela \\ Faculdade Brasileira de \\ Ciências Jurídicas (SUESC). \\ Pesquisadora do Núcleo de \\ Pesquisa sobre Teoria dos \\ Direitos Humanos (NTDH/ \\ UFRJ).alessandra.m.s@ \\ gmail.com
}

SHAKESPEARE, Tom. Disability rights and wrongs revisited. London: Routledge, 2014.

Desde sua publicação, em 2006, Disability Rights and Wrongs é leitura obrigatória aos interessados nos Estudos de Deficiência, sejam pesquisadores, ativistas, bem como gestores públicos. A novidade do trabalho foi desconstruir, corajosamente, o modelo social de abordagem da deficiência, que ganhou o mundo e influenciou, inclusive, a Convenção dos Direitos das Pessoas com Deficiência.

Na presente edição, conforme indica o título, o autor revê alguns dos posicionamentos anteriores e aprofunda discussões. Novos capítulos foram inseridos e seu sumário reorganizado. A primeira edição era subdividida em 3 partes, nas quais o autor abordava o estado da arte dos Disabilities Studies, sobretudo na Inglaterra e países do norte: Conceituando deficiência; Deficiência e bioética; Relações sociais e deficiência.

A segunda edição é dividida em duas partes: Fundamentos; Aplicações. Na primeira são apresentados e discutidos os fundamentos dos discursos contemporâneos acerca da deficiência: o Materialist approaches to disability ou modelo social britânico ${ }^{1}$, cujas análises seguem o Materialismo de cunho Marxista, como se vê em Mike Oliver, Colin Barnes, Vic Finkelstein; o Cultural disability studies, vertente

\footnotetext{
${ }^{1}$ Designado como strong social disability model, o modelo britânico carregaria diferenças quanto ao modelo social defendido em outros países, os quais adotariam perspectivas mais abrandadas e flexíveis, atreladas, por exemplo, às noções de grupos minoritários, como se vê nos Estados Unidos, ou compatibilizando impedimentos e barreiras sociais, como se dá no Brasil, vide art.2ํ da Lei Brasileira de Inclusão da Pessoa com Deficiência (Lei 13.146/2015).
} 
influenciada por autores como Foucault, Deleuze e Guattari, Butler e outros, adentrando em discussões acerca de imaginário cultural, corpo, afetos, paralelos com as experiências de opressão e marginalização de outros grupos minoritários etc.; o Critical realist approaches to disability, abordagem recente de pesquisadores como Simon Williams, Berthe Danermark e Gellerstedt, Nick Watson, Helen Meekosha e Russel Shuttleworth, os quais buscam se afastar de simplificações para alcançar uma perspectiva multidimensional da deficiência, conjugando os diferentes fatores que sobre ela repercutem.

A primeira parte se encerra com um capítulo em que se debate deficiência e identidade, questionando se as pessoas com deficiência efetivamente desejam ser reconhecidas por suas diferenças e quais as consequências políticas em torno da constituição de um grupo deveras heterogêneo em suas formas, demandas e especificidades. Ainda, se as classificações reforçam rótulos, provocam mais afastamento e quais seriam os benefícios de se buscar coalisão com outros grupos minoritários, discussões estas debatidas à luz das análises de Nancy Fraser acerca de reconhecimento e redistribuição.

A segunda parte do livro dedica-se a refletir sobre dilemas atuais, como aborto, diagnóstico pré-natal, cura e reabilitação, suicídio assistido, em sua repercussão sobre a deficiência. Temáticas de ordem social, como liberdade sexual, autonomia, apoio e capacidade, violência também são abordados. A dialética perpassa as bases teóricas lançadas na primeira parte, na tentativa de demonstrar como os principais argumentos dos modelos de abordagem da deficiência são insuficientes em dar respostas sólidas àqueles problemas, levando, algumas vezes, a argumentos de senso comum ou emocionados.

As reflexões e análises são fortemente influenciadas pela trajetória pessoal do autor enquanto pesquisador, ativista e pessoa com deficiência - o autor tem acondroplasia e teve sua condição de saúde agravada desde 2008, motivada por uma lesão na medula espinhal que o levou a usar cadeira de rodas. Da mesma forma, a experiência profissional de trabalho junto à Organização das Nações Unidas (ONU), como membro da Organização Mundial de Saúde (OMS) desde 2006 e integrante do grupo de elaboração do World Report of Disability, de 2011, levou-o a conhecer diferentes realidades e dificuldades experenciadas pelas pessoas com deficiência ao redor do mundo. 
De volta à academia desde 2013, Shakespeare, que tem Ph.D em Sociologia e é professor da Escola de Medicina de Norwich, da Universidade de East Anglia², vem buscando novas perspectivas para compreender seu objeto de estudo e contribuir para o avanço dos Estudos de Deficiência. Ele é autor de outras obras neste campo, valendo destacar a mais recente, Disability (the basics), de 2017, onde explora o modo como os fatores sociais, ambientais, econômicos e legais afetam pessoas com deficiência.

\section{MODELO SOCIAL COMO FERRAMENTA POLÍTICA}

A digressão se inicia com uma reflexão sobre as falhas identificadas pelo autor quanto ao desenvolvimento dos Estudos de Deficiência. A perspectiva do modelo social teria levantado novos questionamentos e gerado outras linhas de investigação para além das tradicionais, então focadas no indivíduo e sua adaptação aos impedimentos ou consequências destes para sua identidade. Tópicos como discriminação, relação entre deficiência e capitalismo industrial, variedade de representações culturais, paralelos entre teorias feministas e raciais, entre outros foram fomentados pelo modelo.

Contudo, Shakespeare entende que a aliança entre política e pesquisa transpôs para a academia ideologia e ativismo, os quais vieram desacompanhados do devido rigor analítico, criticismo e verificação empírica. $O$ ativismo interferiria, também, no pluralismo de fontes e diálogo com diferentes áreas do saber, como, por exemplo, com a Sociologia Médica e a Filosofia Econômica. De fato, o modelo social é tido por alguns pesquisadores como limitador, do ponto de vista científico, por ser tido como verdade hegemônica, que tanto conduz à respostas predeterminadas como desencoraja a busca por novas possibilidades. ${ }^{3}$

Pontos problemáticos em nível conceitual são por ele identificados. O primeiro se referiria à presunção de que as pessoas com deficiência compartilham experiências semelhantes de opressão e restrição. Segundo, a compreensão de deficiência enquanto arranjo social traria um olhar suspeito em relação às tentativas de cura e reabilitação,

\footnotetext{
${ }^{2}$ Informações do autor e contato em sua página pessoal e acadêmica. Disponível em: <https:// farmerofthoughts.co.uk/biography/>. Acesso em: 31 jul. 2019.

3 "The UK social model has thus become an inflexible construction which discourages possibilities for inviting or generating new insights from alternative perspectives". (KRISTIANSEN; KERMIT, 2007, p.279)
} 


Shakespeare
reconhece que
o modelo social
britânico foi
essencial para o
desenvolvimento
do movimento
político das
pessoas com
deficiência,
na medida em
que identificou
uma estratégia
de luta, qual
seja a remoção
de barreiras e
transformação
social.

Shakespeare o modelo social britânico fo essencial para o desenvolvimento político das pessoas com deficiência, na medida em que identificou social. já que a ação principal a ser buscada seria a remoção de barreiras e conquistas de direitos, o que poderia ser obtido por meio de legislação. O terceiro aspecto a se considerar é a visão de deficiência como produto de uma exclusão estrutural e não em termos de experiências individuais. Nesse caso, estatísticas relacionadas à deficiência e o número de pessoas com deficiência não seriam relevantes, pois eliminar as barreiras sociais através de desenhos universais superaria a importância de atender as necessidades especiais das pessoas.

Daí, aponta o autor a relevância da pesquisa empírica qualitativa e quantitativa como ferramenta de análise da realidade das pessoas com deficiência, com vistas a identificar suas demandas, compreender como as barreiras e os impedimentos efetivamente interferem em suas experiências acerca da deficiência. Como resultado, tais pesquisas contribuiriam no fornecimento de dados capazes em se converter em ações para melhorar a qualidade de vida das pessoas. Igualmente, proveria os Estudos de Deficiência de bases epistemológicas sólidas e argumentos seguros para fazer face à questionamentos de ordem econômica, jurídica ou bioética, por exemplo.

Shakespeare reconhece que o modelo social britânico foi essencial para o desenvolvimento do movimento político das pessoas com deficiência, na medida em que identificou uma estratégia de luta, qual seja a remoção de barreiras e transformação social. Outro efeito positivo foi de empoderar as pessoas com deficiência na mobilização por seus direitos como cidadãos iguais, uma vez que era a sociedade que estava em falta com elas e representava elemento de opressão. Por consequência, conquistas na seara legislativa foram obtidas.

Diante disso, afirma, qualquer pesquisador deve dar crédito ao impacto do modelo, sobretudo quanto aos avanços dos movimentos de direitos das pessoas com deficiência em todo o mundo. Por essas razões, entende ele, o modelo social funcionaria mais como ferramenta política do que, propriamente, uma teoria social.

\section{LANÇANDO LUZ SOBRE OS IMPEDIMENTOS}

Conforme Shakespeare, a distinção entre impedimento e deficiência é um dos elementos centrais do modelo social britânico: o impedimento entendido como as limitações do indivíduo; a deficiência tida como uma construção social, onde os impedimentos são tidos como 


A seu ver,
deficiência e
impedimento
estão
entrelaçadas e
não devem ser
separadas: o
impedimento
é influenciado
por fatores
sociais, enquanto
a deficiência
está vinculada
aos efeitos do
impedimento.
Porém, seria o
impedimento que
limita primeiro,
de modo que
as dificuldades
surgem na
combinação entre
os fatores.

um problema, gerando opressão e barreiras à participação social das pessoas com deficiência. $O$ benefício desta abordagem seria retirar o foco da pessoa e suas diferenças, deslocando-o para os processos sociais de inclusão/exclusão, é dizer, o modo como a sociedade isola pessoas que tenham impedimentos.

Por seu turno, a vertente do Cultural Disability Studies analisa a deficiência enquanto categoria, buscando desconstruir a noção binária de deficiente/não deficiente. Assim, impedimentos não seriam uma categoria natural, mas resultado dos discursos e representações sociais e culturais em torno de sua definição e diagnóstico. Com isso, desloca-se a deficiência de um corpo desviante segundo os padrões normativos para o discurso.

Para Shakespeare, a principal falha dos modelos baseados na noção de construção da realidade ${ }^{4}$ consistiria em relegarem os impedimentos a uma posição subjacente, quando, de fato, se tratam de parte importante da experiência pessoal das pessoas com deficiência, da qual, muitas vezes, decorre dor e sofrimento. Citando seu exemplo pessoal, explica como as consequências do impedimento foram e ainda são, em seu caso, maiores e mais limitadoras do que o universo social no qual está inserido e as barreiras dele provenientes.

A seu ver, deficiência e impedimento estão entrelaçadas e não devem ser separadas: o impedimento é influenciado por fatores sociais, enquanto a deficiência está vinculada aos efeitos do impedimento. Porém, seria o impedimento que limita primeiro ${ }^{5}$, de modo que as dificuldades surgem na combinação entre os fatores. Afinal, as barreiras só são percebidas quando alguém tem um impedimento, e os próprios impedimentos decorrem de arranjos sociais que potencializam ou diminuem a restrição, caso sejam modificados em favor ou não da pessoa com deficiência. Além disso, o impedimento somente é vivido num contexto social, sendo certo que o nível de limitação que pode ser tido como impedimento é sempre objeto de julgamento social, pois associado às expectativas e demandas de uma sociedade.

\footnotetext{
${ }^{4}$ Para Shakespeare, as abordagens sobre deficiência informadas por concepções pósestruturalistas e pós-modernistas operariam um social constructionism diferente da teoria clássica de Berger; Luckmann, para quem: "A ordem social não faz parte da 'natureza das coisas' e não pode ser derivada das 'leis da natureza'. A ordem social existe, unicamente, como produto da atividade humana." (BERGER; LUCKMANN, 2012, p.74)

${ }^{5}$ Exemplificadamente, cita o relato de French no livro Disabling Barriers, Enabling Environments, de 1993. Ela possui deficiência visual e relata como sua especificidade interfere na interação em diálogo não verbais, o que não encontraria relação com arranjos sociais.
} 
Daí, definir impedimento em termos meramente biológicos, conforme o modelo social, traria o risco de torná-lo uma categoria essencial, tal qual se dá no modelo médico. Da mesma forma, entender o impedimento como resultado dos discursos e representações sociais, como no Cultural Disability Studies, torna-o categoria artificial, contigente e insatisfatória, levando a que a deficiência possa ser descrita como qualquer restrição ou opressão social, não apenas aquelas experenciadas por pessoas com deficiência. ${ }^{6}$

Essas reflexões colocariam em questão a própria relação entre deficiência/impedimento. Onde se inicia um e termina o outro seria indefinível. Em termos práticos, o que é efetivamente demonstrado em pesquisas qualitativas citadas pelo autor, é que é difícil estabelecer um marco entre deficiência/impedimento, em que pese possa parecer simples teorética e politicamente.

Shakespeare defende, então, que os Estudos de Deficiência se debruçem sobre os impedimentos para compreender e compensar as limitações dele decorrentes, a partir do ponto de vista e perspectivas das pessoas com deficiência. Os conceitos médicos acerca da natureza e significado dos impedimentos devem ser questionados, assim como as respostas com relação à eficácia e efetividade dos tratamentos, efeitos colaterais, fundamento dos estudos e seu atendimento às prioridades das pessoas com deficiência. Devem se ocupar, ainda, da prevenção aos impedimentos, no intuito de proporcionar qualidade de vida às pessoas com deficiência, o que inclui minimizar o impacto dos impedimentos e complicações dele decorrentes.

\section{COMPLEXIDADE DO OBJETO}

A partir das perspectivas do Critical realist approaches to disability, ao qual Shakespeare se alinha, é proposta uma abordagem da deficiência denominada interacional, segundo a qual a deficiência deve ser compreendida como um fenômeno complexo e multidimensional, que envolve aspetos de ordem: física, biológica, psicológica, psicossocial e emocional, socioeconômico, cultural e normativo.

\footnotetext{
${ }^{6}$ O autor alerta para o efeito "guarda-chuva", em que indivíduos que experienciam processos de opressão buscam designação como modo de obterem proteção legal. Nesse sentido, cita a pesquisa empírica de Cooper, em 1997, com mulheres obesas, as quais consideravam que a auto-definição de deficientes atraía seriedade às suas demandas.
} 
Esta visão holística sobre a deficiência tem em conta ser ela uma interação entre fatores individuais e estruturais, ou seja, a experiência da deficiência decorre da relação entre fatores externos e internos ao indivíduo.
Esta visão holística sobre a deficiência tem em conta ser ela uma interação entre fatores individuais e estruturais, ou seja, a experiência da deficiência decorre da relação entre fatores externos e internos ao indivíduo. Como fatores pessoais podem ser considerados a natureza do impedimento, o modo como a própria pessoa lida com esta, sua personalidade, qualidades e habilidades etc. Quanto aos fatores contextuais, podem ser arrolados: o modo como os outros agem frente à deficiência, um ambiente acessível ou não, políticas públicas, aspectos sociais, econômicos e culturais da comunidade, sobretudo com relação à deficiência.

Tais elementos funcionariam em diferentes níveis e de maneira dialética, todos repercutindo sobre a pessoa de algum modo. Por isso que a análise não deve ser reduzida a um ou alguns aspectos da deficiência, conforme vem sendo abordado pelos modelos propostos até o momento, ao darem ênfase ou aos caracteres biológicos ou somente ao social. ${ }^{7}$

A diferença entre uma tal abordagem e o modelo social, como aponta o autor, seria aceitar que os impedimentos existem e constituem uma experiência real, independentemente da descrição a eles dada. Outrossim, confere igual importância ao ambiente e ao contexto, bem assim, discriminação e preconceito são reconhecidos, ciente de que nenhum arranjo social seria capaz de elidir o impedimento em si, por que a deficiência não seria, simplesmente, barreiras e opressão, tampouco se referiria, unicamente, à discriminação, cultura ou linguagem.

Outro destaque seriam as variadas possibilidades de intervenção para melhorar a vida da pessoas com deficiência, incluindo reabilitação, remoção de barreiras e legislação anti-discriminatória, suporte psicológico para lidar com o próprio impedimento, bem como suporte para estarem incluídos na comunidade, redução da exclusão social. A abordagem mais adequada para cada caso individual ou em função da deficiência é considerada pelo autor tema que deve ser debatido.

\footnotetext{
${ }_{7}$ Nesse ponto, a reflexão do autor se alinha à proposta de Morin (2007) quanto ao pensamento complexo, segundo o qual os fenômenos devem ser estudados enquanto unidade, uma vez que a interação entre as partes constituintes compõe a totalidade. O método baseado na disjunção e redução, levaria a uma visão unidimensional e especializada dos objetos e, portanto, reducionista. A rearticulação do conhecimento se daria através de uma abordagem transdisciplinar. No mesmo sentido ver: JAPIASSU, Hilton. O sonho transdisciplinar e as razões da filosofia. Rio de Janeiro: Imago, 2006.
} 


\section{IMPRESSÕES FINAIS}

A quem pretenda enveredar sobre o tema da deficiência, Shakespeare é leitura importante, pois instala uma série de dúvidas onde possa parecer haver somente certezas. Não é de se concordar com o autor em todas as suas críticas, tampouco entender sua proposta como rompimento. Ao apontar pontos negativos ou fracos do campo, o objetivo do autor é desafiar o consenso, perscrutar e questionar suas bases, com vistas a promover debate e depurar os Estudos de Deficiência.

\section{REFERÊNCIAS}

BERGER, Peter Ludwig; LUCKMANN, Thomas. A construção social da realidade: tratado de sociologia do conhecimento. 34.ed. Petrópolis, RJ : Vozes, 2012.

KRISTIANSEN, Kristjana; KERMIT, Patrick. Book Review. Scandinavian Journal of Disability Research Vol. 9, Nos. 34, 278281, 2007.

MORIN, Edgard. Introdução ao pensamento complexo. Trad. Eliane Lisboa. Porto Alegre: Sulina, 2007. 